\title{
Neo-Fascismo, Capitalismo e Educadores Marxistas
}

Dave Hill'

'Anglia Ruskin University, Chelmsford - Reino Unido

RESUMO - Neo-Fascismo, Capitalismo e Educadores Marxistas ${ }^{1}$. Meu foco neste artigo está na educação marxista revolucionária, distinguindo-a, em particular, das versões centrista e de esquerda da socialdemocracia/revisionismo. Nesse sentido, apresento o que considero serem cinco aspectoschave da crítica dos marxistas sobre a política educacional e apresento propostas, e busco cumprir, relacionadas a: (i) Currículo e Avaliação, (ii) Pedagogia, (iii) A Cultura Organizacional dentro da Escola / Instituição, (iv) Organização do Sistema de Ensino e dos Alunos, ou seja, escolaridade integral ou seletiva, e (v) Propriedade e Controle de Escolas, Faculdades e Universidades. A conclusão expõe o que há de especificamente marxista nas propostas apresentadas.

Palavras-chave: Educação Marxista Revolucionária. Educação Contra-Hegemônica. Professores Marxistas. Educação e Classe Social.

ABSTRACT - Neo-Fascism, Capitalism and Marxist Educators. I focus in this chapter on Revolutionary Marxist education, distinguishing it, in particular, from both Centrist, and Left versions of social democracy/revisionism. Accordingly, I set out what I consider to be five key aspects Marxists critique about education policy, and make proposals and seek to enact, relating to: (i) Curriculum and Assessment, (ii) Pedagogy, (iii) The Organisational Culture within the School/ Institution, (iv) Organisation of The Education System and of Students, that is, comprehensive schooling or selective schooling, and (v) Ownership and Control of Schools, Colleges and Universities. The conclusion sets out what is specifically Marxist about the proposals set out.

Keywords: Revolutionary Marxist Education. Counter-Hegemonic Education. Marxist Teachers. Education and Social Class.

Educação \& Realidade, Porto Alegre, v. 46, n. 3, e117660, 2021 
Neo-Fascismo, Capitalismo e Educadores Marxistas

\section{Introdução}

Neste artigo, escrevendo a partir de uma perspectiva Marxista Revolucionária e marxista clássica, identifico e critico três tipos de análise e ativismo socialdemocrata/socialista centrista/Marxista. Quais sejam, (i) socialdemocrata, (ii) socialista democrático/socialdemocrata de esquerda/revisionista/reformista e (iii) Marxista Revolucionário. Debruço-me neste artigo sobre a Educação Marxista Revolucionária, distinguindo-a, especialmente, tanto da Centrista quanto das versões de esquerda da socialdemocracia/revisionismo. Cada um desses três tipos, ou graus, de educação crítica socialista/Marxista está associado a políticas educacionais específicas, derivadas de análises ideológicas/teóricas particulares. Por exemplo, como a análise e o programa Revisionista/Reformista de Esquerda podem ser identificados em Michael W. Apple e, em vários momentos e em vários lugares, em partidos políticos e personalidades sociais-democratas e socialistas democráticos, como Jeremy Corbyn e Bernie Sanders. Igualmente, também é representado pela Pedagogia Crítica não-revolucionária de escritores como Henry Giroux e por milhões de educadores de justiça social ao redor do mundo. Em contraste, a Educação Marxista Revolucionária, ou Educação Comunista, está associada a educadores comunistas históricos (como os primeiros soviéticos) e contemporâneos em todo o mundo, e à Pedagogia Crítico-Revolucionária de Peter McLaren, que deriva da teoria/análise Marxista Revolucionária, bem como (no caso de McLaren) de Paulo Freire/Freireanismo. A Educação Crítica não está restrita a questões da Pedagogia e do Currículo, embora esse seja o foco de muitos educadores críticos, e de grande parte da Pedagogia Crítica. A análise, as propostas e o ativismo têm de abordar questões sociais mais amplas de poder e controle. Nesse sentido, estabeleço o que considero serem cinco aspectos-chave que Marxistas criticam sobre a política educacional, e a partir dos quais apresentam propostas e buscam colocar em prática, relacionadas: (i) ao Currículo e à Avaliação, (ii) à Pedagogia, (iii) à Cultura Organizacional dentro da escola/instituição, (iv) à Organização do Sistema de Ensino e dos Alunos, ou seja, escolas abrangentes ou escolas seletivas $^{2}$, e (v) Propriedade e Controle de Escolas, Faculdades e Universidades. A conclusão explicita o que há de especificamente marxista nas propostas apresentadas. Em resumo: (i) as reformas, como as reformas sociais-democratas ou socialista democráticas, não são duradouras sob o capitalismo; (ii) a fundamentação das análises da educação e da sociedade capitalista e das propostas de educação socialista/comunista (e socioeconômica), com atenção à relevância da análise de classe social e da análise de classe social (de gênero e raça) e da Relação Capital-Trabalho; e (iii) os educadores marxistas devem ser ativistas e revolucionários dentro e fora dos sistemas de educação formal em busca da substituição do capitalismo pelo socialismo, pelas vias do marxismo democrático. 


\section{Fascismo à Espreita: educação crítica, socialista e marxista e educadores sob ataque}

A Educação Crítica, opondo-se às relações de poder em toda a sociedade e propondo e trabalhando em favor de alternativas igualitárias, está sob ameaça global nesta atual era de autoritarismo de direita neoconservador, neoliberal e neofascista. Capitalistas, think-tanks, organizações e governos visam diluir, expelir ou criminalizar a educação socialista, marxista, antinacionalista, principalmente nos currículos e nas atividades de escolas e universidades. Isso não é novidade. É assim que tem sido há séculos. Historicamente bem como atualmente, o neoconservador e o neo/atual fascista também têm como alvo a escrita, o ensino e o pensamentos LGBT, feminista e antirracista (Faulkner et al., 2019, 2021; Hill, 2019a).

No entanto, nesta era atual, do início do século XXI, a educação crítica, que contesta as relações de poder em toda a sociedade e propõe/ trabalha por alternativas igualitárias, está sob excepcional ameaça do autoritarismo de direita neoconservador/neoliberal/neofascista. Isso pode ser observado nos EUA de Trump (e, em muitos estados dos EUA, nos EUA pós-Trump), na Inglaterra e País de Gales de Johnson, no Brasil de Bolsonaro, na Turquia de Erdogan, no governo do Partido da Lei e Justiça na Polônia, na Índia de Modi, na Hungria de Orban e na Ucrânia. Em cada um desses países, forças poderosas procuram diluir, expulsar ou criminalizar a educação socialista, marxista e antinacionalista - principalmente nos currículos e atividades das escolas e universidades. Uma das mais notáveis é a política do pretenso governo fascista de Bolsonaro no Brasil, que promete durante sua campanha eleitoral de 2018 “[...] entrar no Ministério da Educação com um lança-chamas para remover Paulo Freire” (Woods, 2020, n.p.). Desde sua eleição em 2019, seu partido político fez campanha para encorajar estudantes universitários e do ensino médio a secretamente filmarem seus professores e a denunciá-los por doutrinação ideológica (Buarque et al., 2020), o que em si não é uma nova tática antiesquerda. Peter McLaren estava no topo da lista Dirty Thirty de educadores progressistas na UCLA (EUA); os alunos eram pagos para enviar gravações de suas palestras a uma organização de direita. Nesse contexto, McLaren é um dos muitos, em diferentes países e continentes, a alertarem e exporem a guerra contra o pensamento crítico (Fassbinder; McLaren, 2006), um aviso regularmente disseminado por radicais como Henry Giroux, Paul Street, David Graeber, Noam Chomsky e Peter McLaren.

O punho de ferro do Capital e suas estruturas limitam severamente a atividade de resistência, punindo, restringindo e criminalizando, por exemplo, sindicatos e ativistas políticos de esquerda e o pensamento de esquerda anticapitalista. Como exemplo, em setembro de 2020, as escolas na Inglaterra foram orientadas pelo Ministério da Educação a não utilizar material associado a grupos anticapitalistas, sendo que o anticapitalismo foi categorizado como uma postura política extremista equivalente ao endosso de atividades ilegais (Busby, 2020). Em resposta,

Educação \& Realidade, Porto Alegre, v. 46, n. 3, el17660, 2021. 
o parlamentar de esquerda do Partido Trabalhista (Labour Party), John McDonnell, argumenta: "Com base nessa premissa, será ilegal referir-se a longos períodos da história e da política britânica, incluindo a história do socialismo britânico, do Partido Trabalhista e do sindicalismo, todos os quais, em diferentes momentos, defenderam a abolição do capitalismo" (Busby, 2020). É uma tentativa de estender e intensificar o controle do pensamento. Como outro exemplo, na Polónia, possuir uma cópia d'O Capital, de Marx, é ato passível de punição com três anos de prisão (Stańczyk, 2021). Na Turquia, muitos membros da esquerda e educadores marxistas foram demitidos e perderam direitos sociais e públicos, incluindo seus passaportes, após o golpe fracassado de julho de 2016 (no qual não estiveram envolvidos) contra o presidente Erdogan; e, atualmente, na primavera de 2021, os governos da Grécia e da Turquia estão tentando exercer mais controle sobre as universidades.

Embora seja verdade que os Aparelhos Ideológicos do Estado (Althusser, 1971) (como Ministérios da Educação e órgãos governamentais que regulam escolas e universidades) tenham em suas funções ideológicas e repressivas, em graus diversos, buscado marginalizar, conter, difamar e destruir programas marxistas (e, certamente, socialdemocratas de esquerda, como os de Jeremy Corbyn e Bernie Sanders), nesta conjuntura estamos testemunhando e sofrendo uma intensificação da repressão ideológica. E ainda que a repressão física, o assassinato em massa, a eliminação de membros da esquerda em sindicatos, organizações comunitárias e aparelhos educacionais não esteja na escala dos massacres anticomunistas, como o das forças estatais da Indonésia, apoiadas pela CIA, ou dos Contra, também com apoio da CIA, em países da América Latina, como Chile, Brasil, Argentina, Nicarágua, Guatemala, o assédio e as demissões de educadores e ativistas marxistas tem aumentado de país em país. Atualmente,

Podemos identificar quatro componentes principais do fascismo contemporâneo: o papel dos partidos de extrema direita na construção de um bloco eleitoral reacionário de massas; o papel da Internet na disseminação da propaganda de extrema direita e na criação, consolidação e mobilização do núcleo fascista; o papel do Estado burguês, especialmente da polícia cada vez mais militarizada, na implementação de políticas autoritárias e nacionalista-racistas e repressão dos movimentos populares; e o papel de colaboração das manifestações e milícias fascistas (Faulkner et al., 2021, n.p.).

Estes são tempos particularmente perigosos - o generalizado declínio e deslegitimação do neoliberalismo e da economia e política de austeridade - para marxistas, professores e educadores radicais de esquerda, pensadores críticos e ativistas. O único tipo de pensamento crítico considerado desejável por tais autoritários de direita é um questionamento tecnicista e conservador descontextualizado e despolitizado, que deixe o confortável confortavelmente incontestado e no seu devido lugar e os inimigos do fascismo mortos nas ruas e nas celas das prisões. 
Estes são os tempos do Fascismo à espreita ${ }^{3}$ (Faulkner et al., 2019; 2021). Este artigo é uma pequena parte dos processos de construção da resistência anticapitalista e antifascista nas mentes e nas ruas e de construção do marxismo revolucionário dentro da sala de aula, no local de trabalho, no movimento social e nas ruas.

\section{Três Tipos de Educação Socialista, Três Tipos de Educação Crítica}

Neste artigo, não estou discutindo versões conservadoras-tecnicistas ou pluralista-liberais ou neutras em sala de aula da Educação Crítica. Em vez disso, analiso criticamente três tipos de educação crítica de esquerda.

Social-democratas de centro querem reformar a educação (tornála um pouco mais justa, mais meritocrática, com algum nível de discriminação positiva). Mais à esquerda, socialistas democráticos ou socialdemocratas de esquerda/reformistas de esquerda, como Jeremy Corbyn e Bernie Sanders, também querem reformar a educação para torná-la muito mais justa, com um nível mais elevado de discriminação positiva, para que se possa apoiar grupos historicamente sub-representados.

Marxistas Revolucionários, isto é, marxistas que buscam a substituição do capitalismo pelo socialismo, visam uma educação crítica do capitalismo, uma educação para a transformação social, política e econômica, em direção à economia e à sociedade socialista. Em meus próprios escritos, grande parte disponível online ${ }^{4}$, fundamentados a partir de uma perspectiva Marxista Revolucionária e Marxista Clássica, defendo uma política de educação marxista (por exemplo, Hill, 2010, 2015, 2019a, 2019b, 2019c; Rasinski; Hill; Skordoulis, 2018; Edwards; Hill; Boxley, 2018; Gonzalez; Rikowski, 2019). Debruço-me sobre a educação marxista, diferenciando-a da política educacional socialdemocrata centrista, socialdemocrata de esquerda e socialista democrática, incluindo versões liberais e socialdemocratas e socialistas democráticas da Pedagogia Crítica.

\section{Socialdemocratas Centristas e Socialdemocratas de Esquerda/ Socialistas Democráticos e a Educação}

Os socialdemocratas desenvolveram políticas destinadas a tornar o sistema mais meritocrático. Com políticas de igualdade de oportunidades que incluem a ideia de discriminação positiva em favor de grupos sub-representados (em particular, as camadas mais pobres da classe trabalhadora e grupos étnicos específicos), a ascensão acadêmica e escolar e futuras posições no mercado de trabalho decorrentes da relação entre esforço mais habilidade, ou seja, mérito para a entrada em uma sociedade brutalmente desigual.

Os sistemas educacionais socialdemocratas tradicionais são aqueles como os da Suécia e Finlândia e as reformas do governo de Wil- 
Neo-Fascismo, Capitalismo e Educadores Marxistas

son Labour na Inglaterra e País de Gales nos anos 1960 e 1970 . Wilson estabeleceu de forma ampla (talvez, universalmente no sistema estadual porque as escolas privadas permaneceram fora do sistema estadual) uma educação universal e comum, bolsas para ajudar crianças de famílias mais pobres (como eu) a permanecerem na escola, e subsídios (Bolsas de Apoio à Educação) para a universidade, na tentativa de promover uma Educação Compensatória. Foram amplamente difundidas políticas, tais como as de salas reduzidas para alunos de baixo rendimento, colégios internos e viagens culturais, de todas as quais me beneficiei e me recordo como aluno, professor e como conselheiro local. No nível pós-escolar, a educação gratuita de adultos era ubíqua tanto como forma de lazer quanto como um nível de formação complementar vocacional. A Universidade Aberta ${ }^{5}$ foi implantada para que aqueles que tivessem deixado a escola na idade mínima permitida ou aos 18/19 anos pudessem estudar para obter um diploma (majoritariamente por meio da educação a distância), gratuitamente, livre de quaisquer taxas, enquanto ainda estivessem trabalhando.

Em várias etapas e em vários países, todos os tipos de socialistas tentaram, em vários momentos, construir um currículo escolar mais inclusivo e relevante para diferentes comunidades e classes. $\mathrm{O}$ movimento Escolas Comunitárias, particularmente forte na Inglaterra entre 1970 e 1990, tentou tornar as escolas em elementos mais centrais nas comunidades locais, por meio da implementação das escolas comunitárias, que diminuiriam a distância entre a escola e as comunidades da classe trabalhadora. O movimento Escolas Comunitárias "[...] busca suprimir as fronteiras entre a escola e a comunidade para transformar a comunidade em escola e a escola em comunidade" (Halsey, 1972, p. 79); assim como o fez o negligenciado Relatório Hargreaves sobre a educação secundária na Inner London Education Authority (ILEA, 1984, sintetizado por Doe, 1984).

No entanto, sociólogos da educação nos últimos 70 anos (Floud; Halsey; Martin, 1957; Halsey; Heath; Ridge, 1980), e comunistas e socialistas antes disso, ver Simon (1965; 1978), e, mais recentemente, Stephen Ball (2003), Jean Anyon (2011) e Diane Reay (2018), apontaram o sólido mito da meritocracia nos sistemas de ensino. Teóricos marxistas da reprodução, desde os primeiros escritores soviéticos, como Bukharin e Preobrazensky (1922/1969), até teóricos marxistas contemporâneos, como Glenn Rikowski (passim) e Dave Hill (passim), com base, até certo ponto, em Bowles e Gintis (1976) e Bourdieu e Passeron (por exemplo, 1977), Anyon (por exemplo, 2011), há muitas décadas, apontam que o sistema educacional é propositada e intencionalmente manipulado em favor da classe capitalista de elite e em favor da reprodução de classe.

Teóricos marxistas e ativistas, junto com teóricos e ativistas socialdemocratas, concordam também que dentro da classe trabalhadora, a esfera da classe média assegura vantagem de posição - melhores escolas, universidades (notas e resultados) - se comparada às esferas menos favorecidas, mais pobres da classe trabalhadora, dentro das quais determinados grupos étnicos e de gênero alcançam menos que outros 
e estão sujeitos a níveis muito maiores de opressão - racismo, sexismo, homofobia - do que outros grupos.

Essas reformas socialdemocratas, embora geralmente centradas na pedagogia e no currículo, foram promovidas por muitos Pedagogos Críticos, como Henry Giroux (por exemplo, 1983, 2001), e também por educadores marxianos, como o muito influente Michael W. Apple (por exemplo, 2006), e seus co-pensadores, como Ken Saltman (por exemplo, 2010), Ken McGrew (por exemplo, 2011). Esses podem ser considerados socialistas-democráticos, que desejam que professores estejam comprometidos com o antirracismo, com o ensino da justiça social, e com o desenvolvimento de professores como intelectuais da transformação, que buscam uma sociedade mais justa. Esses socialdemocratas de esquerda, ou socialistas democráticos, querem reformas substanciais - dos sistemas mais amplos da economia, do sistema penal, da política, do bem-estar social e da educação, mais chances iguais (acesso, financiamento e conquista).

Foley et al. (2015, p. 110) apontam que a “[...] pedagogia crítica entrou na ordem do convencional nos Estados Unidos, com mais de 7.000 títulos que abordam o tópico sendo oferecidos na grande varejista de livros Amazon.com". Eles estão fundamentados em Gramsci e na Escola de Frankfurt e buscam aplicar Freire e pedagogos críticos para a transformação da consciência. Em comparação aos marxistas estruturalistas, os neomarxistas culturais, como os proponentes e escritores da Pedagogia Crítica, veem maior espaço para a autonomia de indivíduos, grupos e instituições/organizações (como escolas) para se engajarem em práticas de resistência e em uma práxis anti-hegemônica. A Pedagogia Crítica tem sido elogiada e praticada e, também, amplamente criticada.

No entanto, McLaren, por exemplo $(2000 ; 2021)$ observa que a Pedagogia Crítica, (em oposição à sua própria Pedagogia Revolucionária - isto é, Pedagogia Marxista Crítica) -

\begin{abstract}
[...] pelo menos nas salas de aula dos Estados Unidos) [é] pouco mais do que o liberalismo remodelado com alguma ajuda lexical de Freire (com o uso de palavras como práxis e diálogo) e é basicamente usada para camuflar as relações sociais capitalistas existentes sob uma infinidade de declarações irênicas e estratégias para a sala de aula (McLaren, 2000, p. 25). Para críticas semelhantes, ver também Gibson, (2008), McLaren (2016; 2021), Au, (2017), Stańczyk (2021).
\end{abstract}

Isso, de forma alguma, serve para degradar os esforços daqueles professores e educadores que tentam trabalhar por uma cidadania crítica e pela justiça social em salas de aula e seminários/palestras ou online, nem os compiladores dos vários compêndios/coleções editadas sobre Pedagogia Crítica. O que eles não querem é a revolução marxista, a substituição do capitalismo e da educação capitalista pelo socialis$\mathrm{mo}^{6}$. Anyon (2011) identifica os marxistas revolucionários como mar- 
Neo-Fascismo, Capitalismo e Educadores Marxistas

xistas tradicionais e os socialdemocratas de esquerda, como Michael W. Apple, como neomarxistas.

Os marxistas clássicos criticam o neomarxismo, embora, assim como Marx, Lênin e Luxemburgo, acolham as reformas, sem serem reformistas. Retomando um argumento anterior e importante, não são apenas os aparelhos do Estado capitalista (e os aparelhos de apoio ao Estado capitalista, como a mídia) que disciplinam a classe trabalhadora, é também a guerra econômica, a força bruta e o poder da classe capitalista no domínio do trabalho, do emprego, na supressão e repressão salarial e na miséria. Este é um exemplo de uma instância em que a análise marxista clássica está em desacordo com as análises neomarxistas, em que o cano da arma comandada pela classe capitalista esmaga a relativa autonomia de resistência, em que a sobredeterminação é suplantada pela determinação econômica.

Minha crítica ao neomarxista Althusser (Hill, 2001; 2005) foi à sua formulação de que Determinação Econômica em Última Instância significa “[...] na última 'sobredeterminada”” análise (Althusser, 1962, n.p.). Embora Althusser tenha admitido "[...] a determinação econômica em última instância”, ele acrescenta uma importante qualificação, que, em minha perspectiva, nega a primeira, de que na forma sobredeterminada seu sino nunca tocou.

\section{Cinco Aspectos da Educação Marxista}

Os marxistas revolucionários, isto é, os marxistas que são anticapitalistas e desejam ver o capitalismo substituído pelo socialismo, desejam um sistema de educação que não seja apenas gratuito (livre de taxas), na infância e ao longo de toda a vida, mas que seja um sistema com professores bem formados, que sejam bem pagos e valorizados na sociedade, em escolas e universidades marxistas, com um currículo que denuncie o capitalismo e as desigualdades, defenda o socialismo e os valores solidários em oposição às atividades escolares individualistas e competitivas. Em um sistema educacional marxista, todas as escolas e universidades, inclusive as privadas, seriam submetidas ao controle democrático local. Não haveria nenhuma escola ou universidade privada.

\section{As Perguntas que os Educadores Marxistas Fazem}

Em escolas, faculdades, universidades, muitos educadores radicais e críticos marxistas tentam, além de buscar aumentos dramáticos no financiamento, trabalhar com cinco aspectos da aprendizagem e do ensino, questionando (pelo menos) cinco aspectos da educação. Elas estão relacionadas i) ao Currículo e à Avaliação, (ii) à Pedagogia, (iii) à Cultura Organizacional dentro da escola/instituição, (iv) à Organização do Sistema de Ensino e dos Alunos, ou seja, escolas abrangentes ou escolas seletivas, e (v) à Propriedade e Controle de Escolas, Faculdades e Universidades. 
Essas questões são comuns a muitos tipos de educadores radicais, de liberais a socialdemocratas e socialistas-democráticos, não somente marxistas. Abaixo, portanto, eu acrescento o que é especificamente marxista sobre esses cinco aspectos da política e da práxis educacionais (veja Hill, 2019a; 2019b; 2019c).

\section{(i) Currículo e Avaliação}

A primeira pergunta de marxistas e outros educadores críticos é: o que deveria estar no currículo? Uma questão relacionada é: quem deve decidir? O currículo deveria ser um currículo para a conformidade - para criar trabalhadores e cidadãos conformistas e zelosos, desprovidos de uma crítica sagaz (da sociedade existente, por exemplo)? Deveria ser um currículo branco, masculino, de classe média, não influenciado pela teoria da descolonização, pelo Black Lives Matter, por feminismos, como a Teoria da Reprodução Social de Tithi Bhattacharya (2017)? Ou, como os marxistas propõem e praticam, deveria ser um currículo para reforma e revolução, em que as áreas/disciplinas curriculares (ou projetos/temas interdisciplinares) se debruçassem sobre as desigualdades, sobre a resistência, sobre a transformação, sobre o bem coletivo, sobre o não-consumismo individualista, sobre o ambientalismo e não sobre o ecocídio capitalista. Assim, a geografia incluiria um foco na geografia social, a ciência nas implicações sociais da ciência e a história e a literatura e as artes englobariam brancos, negros, homens e mulheres, a história da classe trabalhadora e romances e peças que deflagrariam injustiças de raça, gênero e classe social, por exemplo, e promoveriam o socialismo e o comunismo. O currículo seria descolonizado e revolucionado. Seria antirracista, antissexista, ambientalista, marxista. (Também desenvolveria conceitos, habilidades e conhecimentos específicos dentro das áreas).

Educadores marxistas, na verdade, educadores críticos em geral, podem, com os alunos, olhar para o currículo e perguntar: O que você acha/nós achamos que deveria estar no currículo e que está ausente atualmente?, Quem vocês imaginam que ganha e quem perde com esse currículo?, Existe uma versão ou perspectiva diferente do passado, do presente, ou do futuro? Quais mensagens são veiculadas nesse currículo sobre, por exemplo, poder, protestos, individualismo, coletividade/coletivismo, Black Lives Matter, Geração X e ambientalismo, sexismo e misoginia, sexualidade e opressão e exploração de classe? Onde Marxistas e Educadores Críticos Revolucionários (McLaren, 2010; 2013) diferem de educadores socialdemocratas, socialistas democráticos e liberais é na ênfase dada à resistência, ao ativismo e à transformação socialista, e à análise de classe social.

Em relação à Avaliação, o que é geralmente avaliado é o que os professores colocam em evidência. Posso ficar restrito a conhecimentos e habilidades do tema ou ir mais além. O (socialdemocrata) Relatório Hargreaves sobre a educação na Inner London Education Authority (ILEA, 1984; Doe, 1984) que é dominada pela esquerda, por exemplo, 
propôs que os índices de aproveitamento dos alunos incluíssem não apenas os resultados dos exames, mas também o aproveitamento dos alunos em áreas como resolução de problemas, habilidades pessoais e sociais e motivação e comprometimento. Além disso, recomendava que os alunos tivessem voz ativa nas políticas escolares, como no currículo e nos exames.

Em outros trabalhos (por exemplo, Edwards; Hill; Boxley, 2018), apresentei um Manifesto pela Educação, em parte com base em uma tentativa de elaboração de um curso marxista de formação de professores. Muitas dessas propostas são apoiadas por outros grupos de reforma e justiça social. Juntos, eles oferecem um persistente desafio ao capitalismo neoliberal/neo-conservador e pre-/proto/quasi fascista.

\section{(ii) Pedagogia}

Muitos educadores marxistas (e outros educadores críticos) questionam a pedagogia esmagadora que é centrada no professor, o padrão de relacionamento e interação entre ensino e aprendizagem, o que Freire chamou de modelo bancário de educação. Em vez disso, usando perspectivas e a práxis Freireanas, eles buscam adotar uma pedagogia participativa e democrática que possa romper, em certa medida, com os padrões de dominação e submissão, e que seja uma pedagogia que ouça as vozes das crianças, dos alunos e das comunidades locais. É uma pedagogia que fundamenta o ensino e a aprendizagem nas inquietações e nos problemas do cotidiano. Além disso, é uma colaboração entre professores e alunos. A aprendizagem é colaboração, não individualismo e competição. É um sistema pedagógico - em um padrão de relações de ensino e aprendizagem - que é coletivo, colaborativo e de apoio mútuo.

Além da pedagogia colaborativa, participativa e democrática, os educadores marxistas críticos usam diferentes tipos de pedagogia no ensino para se engajarem no ensino e na pesquisa não-hierárquica, democrática e participativa. Vygotsky (1934), como um marxista, inspirado pela dialética de Marx, rejeita versões de cima para baixo e de baixo para cima do processo de aprendizagem - esses modelos unidirecionais se originam em relações sociais de classe que os marxistas rejeitam.

$\mathrm{Na}$ Inglaterra, a pedagogia do ensino fundamental foi removida, em certa medida, do controle dos professores. Em consonância com a National Literacy Strategy (NLS), uma estratégia específica de ensino e aprendizagem foi recomendada, fiscalizada e inspecionada e, por mais de uma década, suas prescrições ainda foram sentidas. Em todas as disciplinas do currículo, as aulas seguiram um padrão de quatro partes: uma introdução, aula/ a explicação do professor/o professor como centro, trabalho de discussão entre os alunos e uma plenária. Não há espaço para as perspectivas de ensino e aprendizagem Freirianas, Vygotskyanas ou liberais-progressistas centradas na criança, nenhum espaço para a síndrome do gato morto voando pela janela, por meio da qual professores e alunos poderiam explorar um acontecimento inesperado. E não há espaço para o trabalho interdisciplinar em grupos mais 
amplos e a análise de um problema ou evento social específico, o tipo de ensino escolar e de formação de professores de que participei entre o final dos anos 1960 e o final dos anos 1980. Em vez disso, não há tempo - o currículo está cheio de conteúdo elaborado por think-tanks, conselheiros e ministros conservadores (Jones, 1989; 2003; Hill, 1994; 1997).

Retomando as questões da pedagogia, naturalmente, as críticas à pedagogia dominante, centrada no professor, não estão restritas aos educadores marxistas. Elas também são feitas por educadores liberaisprogressistas, educadores que priorizam a criança/aluno como centro, educadores anarquistas e por alguns educadores conservadores, preocupados com a eficácia do ensino e com a preparação para o mercado de trabalho. De acordo com Gramsci, os professores marxistas, em virtude de seu papel social e ideológico de realmente ensinarem, de realmente desempenharem o papel de professores, deveriam manter uma certa postura autoritária quando apropriado. Há espaço para aulas expositivas e palestras bem como para o ensino por meio do dialógico e do debate e para uma aprendizagem baseada tanto nas necessidades do indivíduo quanto da comunidade.

Os educadores marxistas diferem entre si (assim como os educadores conservadores) no que diz respeito à questão de se a educação é ou deveria ser proselitismo, por exemplo, enaltecendo a revolução, e em que grau ela é/deveria ser crítica (incluindo a autocrítica), criticando não apenas o capitalismo e a desigualdade, mas também as ideologias, políticas e práxis atuais e alternativas. É como um fantasma que atravessa épocas e lugares, da pedagogia autoritária à democrática, desde alguns estados Comunistas em períodos específicos a alguns movimentos insurgentes.

Minha própria análise teórica marxista clássica e práxis marxista revolucionária, desenvolvida a partir de uma enorme consciência pessoal e teórica da desigualdade de classe e resistência, visa uma síntese da pedagogia vygotskyana, freiriana e gramsciana. Minha própria práxis inicial como um jovem professor (na Stockwell Manor Comprehensive School em Brixton, no interior de Londres) ocorreu durante o período de educação relativamente liberal-progressista e centrado na criança na Inglaterra no final dos anos 1960 e início dos anos 1970. Isto é, antes do discurso de James Callaghan, Primeiro-ministro do Partido Trabalhista, no Ruskin College de 1976, que deu início ao processo de retomada da educação para o cumprimento de objetivos primordialmente econômicos e vocacionais. Um processo levado a efeito e conclusão, que foi seguido pelos governos Thatcher e Major de 1979 a 1987. Aquela foi também uma época de ensino socialista e elaboração curricular em algumas escolas estaduais, numa época em que não havia currículo nacional, escolas e professores puderam desenvolver seus/nossos próprios currículos. $\mathrm{O}$ puro ódio, tanto ao liberal-progressista quanto às tentativas de educação crítica socialista igualitária, é descrito nos livros de Ken Jones $(1989 ; 2003)$ e em meus próprios escritos (por exemplo, Hill, 1997; Hill; Cole; Williams, 1997), e detalham as reações dos políticos conservadores e o puro veneno dirigido às crianças progressistas-libe- 
Neo-Fascismo, Capitalismo e Educadores Marxistas

rais, bem como à educação socialdemocrata e socialista e a determinação de esmagá-los a todos. Como afirmado, a legislação conservadora a Lei de Reforma da Educação de 1988 e sua introdução de um Currículo Nacional obrigatório, rigidamente supervisionado e inspecionado para as escolas, e o currículo nacional igualmente controlador e conservador para a formação de professores de 1991/1992 - viu a remoção de muitos professores e formadores de professores de esquerda de seus empregos. Eu fui um daqueles demitidos, despejados (ver Hill, 2004).

\section{(iii) A Cultura Organizacional Dentro da Instituição Escola / Universidade}

Uma terceira questão para a educação diz respeito às relações sociais e às relações de poder entre o espaço de gerência/coordenação e os outros trabalhadores da educação, isto é, entre a cabeça da universidade/escola, os diretores, e os professores, os palestrantes e a equipe de funcionários. E diz respeito também ao currículo oculto nas relações, demandas e expectativas da tríade diretor-professor-aluno.

A cultura da escola é democrática e colegiada ou é ditatorial e autoritária? Isto está também relacionado às diferenças de remuneração entre aqueles no alto escalão e aqueles na sala de aula. Antes da diversificação da educação pública, em Inglaterra e no País de Gales, em Faculdades Tecnológicas Municipais e Academias, professores e diretores eram empregados pelas autoridades educacionais locais, os Conselhos democraticamente eleitos. Havia escalas salariais nacionais, nenhuma negociação salarial individual e busca de remuneração por desempenho, e nenhum diretor ganhava muito mais do que o PrimeiroMinistro, como é o caso de alguns diretores de Academias e Diretores de Cadeias de Academias. Tal como acontece com outros setores quase e parcialmente estatais, com o Novo Gerencialismo Público, a diferença de salários e emolumentos entre os que estão no topo e os trabalhadores cotidianos, como professores e palestrantes, aumentou.

Em nível global, e no Reino Unido, onde o neoliberalismo triunfou na educação, os resultados comuns foram o aumento da precarização do trabalho acadêmico, aumento da proletarização, aumento das diferenças de salários e de condições dentro dos setores de educação, cortes nos salários e remunerações (e também no chamado salário social, de benefícios e direitos), pagamento por resultados/remuneração por desempenho, cortes na escola e nos orçamentos de ensino superior e complementar, maior intensificação do trabalho, com turmas maiores, diminuição da autonomia dos professores de escolas e faculdades sobre currículo e sobre a pedagogia, sujeitos à vigilância e rigidez do novo gerencialismo público, níveis aumentados de monitoramento e elaboração de relatórios, e consequentes níveis crescentes de estresse, maior preocupação com a cronometragem e códigos de disciplina mais rígidos e punitivos. O terror das rondas de diretores e membros do SMTs (Senior Management Teams ou equipes de gerenciamento sênior), que tinham autorização para entrar em qualquer aula e por quanto tempo quises- 
sem. Há também a restrição dos direitos sindicais e os ataques aos sindicatos como organizações que defendam e promovam os interesses da classe trabalhadora.

Isso está muito longe da abordagem ocasional em colegiados da democracia escolar e da gestão mais progressista e, em algumas escolas, mais socialista. Em minha própria experiência como professor de uma escola de educação infantil em meados da década de 1980, todo o corpo docente se reunia para discutir a política escolar com esquemas de leitura e o diretor da escola agia mais como um presidente do conselho do que como um ditador.

Em Portugal, sob o neoliberalismo, a tradição de uma gestão colegiada e democrática legalmente instituída nas escolas, segundo a qual os funcionários escolares elegiam os seus diretores, o presidente do conselho diretivo (Castanheira; Costa, 2011) (com candidatos a diretor, muitas vezes concorrendo com candidaturas de partidos) durou até 2008, quando o governo português reconheceu "[...] a necessidade de desenvolver uma liderança forte na gestão de uma escola, substituindo a gestão colegiada por um órgão individual - um diretor" (Castanheira; Costa, 2011, p. 210).

A cultura escolar gerencialista também está longe de ser uma característica do Relatório Hargreaves para as escolas de Londres (ILEA, 1984), que deveria dar aos alunos oportunidades de representação na gestão da escola, por exemplo, por meio dos conselhos escolares (compostos por representantes do corpo discente, além de um certo grau de envolvimento do professor), tendo poderes não apenas sobre trivialidades, como banheiros, comida e lixo, mas também sobre questões como horário escolar, atividades extracurriculares e (como mencionado anteriormente) sobre o currículo e a avaliação e sobre o currículo e os exames, para dar aos alunos a experiência dos procedimentos democráticos.

Parte do processo de redução dos níveis de criticidade e profissionalização dos professores e de cortes nos salários é a proletarização dos professores e, cada vez mais, da precarização do ensino nas universidades, tendo ocorrido um aumento no nível de identificação, por parte dos professores e seus principais sindicatos, como o National Education Union na Inglaterra e País de Gales, e profissionais da educação com o movimento da classe trabalhadora, a luta dos trabalhadores e a ação industrial. Isto se deve pela intensificação da consciência de classe da classe trabalhadora. O National Education Union (NEU) e o Universities and Colleges Union (UCU) têm sido os dois sindicatos que lutam com mais sucesso contra as variadas medidas dos governos Conservadores, como a não-abertura das escolas até que a situação esteja mais segura em relação ao Covid.

\section{(iv) Organização dos Estudantes e do Sistema Educacional}

Uma quarta questão da educação que os educadores críticos e marxistas podem e deveriam fazer é sobre a organização dos estudantes. 
Neo-Fascismo, Capitalismo e Educadores Marxistas

Como devem as crianças de diferentes classes sociais, gêneros e etnias se organizar dentro das salas de aula, dentro das instituições, escolas e universidades, e dentro dos sistemas de educação nacional?

Os Marxistas preferem e trabalham em favor do que, na Grã-Bretanha, é chamado de escolas abrangentes e, na Índia, de escola comum. Socialistas de vários tipos argumentam que a escola deve ser um microcosmo da sociedade, que cada escola deve conter uma mistura de crianças/estudantes de diferentes classes sociais e estratos sociais, e uma mistura de diferentes níveis de rendimento/desempenho. Ou seja, crianças/estudantes não devem ser divididos entre alto desempenho e baixo desempenho ou por classe social. Além disso, eles não devem ser divididos por riqueza/renda. Portanto, não deve haver escolas ou universidades privadas, conforme observado abaixo. Nenhuma parte da população com dinheiro ou relativamente bem de vida deve ser capaz de comprar vantagens educacionais e, assim, prejudicar outras pessoas. $\mathrm{O}$ valor pago por uma semana para uma criança no Eton (Maisuria, 2020) é o valor que muitas famílias têm para sobreviver em uma semana.

Sob o regime de desempenho acadêmico da mercantilização competitiva de escolas, crianças/alunos de até quatro anos de idade são agrupados por capacidade/habilidade ou por receita/classe. Isso é muito diferente da organização de habilidades mistas de muitas escolas nas décadas de 1960 e 1980 e muito diferente das propostas do Hargreaves e dos Relatórios Thomas sobre a Educação Primária e Secundária na Inner London Education Authority (ILEA 1984, Thomas, 1985; resumidos, respectivamente, em Doe, 1984; 1985).

\section{(v) Propriedade, Controle e Gestão de Escolas, Faculdades e} Universidades

Uma quinta questão que os marxistas revolucionários colocam é sobre quem deve possuir, controlar e governar escolas, faculdades de educação continuada (vocacionais) e universidades. Deve ser o povo? Municípios/conselhos locais? Especuladores ou fundos de investimentos? Igrejas e mesquitas?

Educadores marxistas revolucionários (e outros, é claro) acreditam que escolas, faculdades e universidades devam ser administradas democraticamente, com trabalhadores e estudantes da educação, bem como por representantes eleitos das comunidades locais, tendo poderes dentro e sobre essas instituições de ensino, dentro de um sistema laico e de um quadro democrático nacional. Não deve haver controle privado de escolas, faculdades ou universidades, seja por empresas/acionistas privados, organizações religiosas ou indivíduos privados. A mercantilização e a marketização da educação devem acabar (Rikowski, 2019). Assim, não deveriam existir as Academias na Inglaterra, nenhuma Charter School, seja sem fins lucrativos ou com fins lucrativos, nos EUA. (Para tentativas de abordar esses vários aspectos da educação, no desenvol- 
vimento de uma política socialista para a educação, consulte Hill, 2010, 2013, 2015; 2019; Ford, 2016; Edwards; Hill; Boxley, 2018).

\section{O Que É Especificamente Marxista sobre essas Propostas Políticas?}

O que define os marxistas é em primeiro lugar, a crença de que as reformas não são sustentáveis sob o capitalismo, elas são eliminadas quando há crises (recorrentes e sistêmicas) do capital, como as das décadas de 1930, 1970 e, atualmente, o pós-2008, e como é provável que sejam na era pós-Covid-19 (por exemplo, com cortes salariais e direitos sindicais e orçamentos sociais sob nova ameaça).

A segunda diferença é um entendimento da proeminência da classe em comparação com outras formas de opressão estrutural e discriminação e desigualdade. Os marxistas vão além de criticar (e agir contra) a discriminação social, opressões, por exemplo, de gênero, homofobia, racismo, em direitos econômicos e no reconhecimento de que direitos econômicos plenos não podem ser alcançados sob um sistema econômico capitalista, mas apenas sob um sistema socialista ou comunista. Os currículos formais e informais deveriam ensinar a análise marxista da sociedade, sua natureza baseada em classes (em termos teóricos, a Relação Trabalho-Capital). O objetivo é desenvolver consciência de classe, ou, como disse Marx, a classe trabalhadora como uma classe para si mesma, não simplesmente como uma classe em si mesma (Marx, 1852/1999), o que Gramsci chamou de bom senso, em oposição a senso comum (Gramsci, 1971/2000).

O terceiro ponto de diferença entre socialistas marxistas e nãomarxistas é que, para substituir o capitalismo, os marxistas têm de realmente trabalhar para se organizar para esse movimento, para essa ação. Assim, um dever do professor Marxista Revolucionário é ser ativista, e o reconhecimento de que a organização política, o desenvolvimento de programas e a intervenção são necessários. O que é preciso é uma revolução para substituir, para nos livrarmos do sistema econômico capitalista.

Esses são três pontos de diferença entre marxistas e outros socialistas, entre o que é marxista e o que não é (Hill, 2018; 2019a; 2019b, 2019c).

\section{A Tarefa e o Papel dos Educadores Marxistas}

O papel dos intelectuais orgânicos públicos marxistas é crucial. Intelectuais públicos marxistas - como o político representante sindical ou o organizador sindical, o membro de um partido ou grupo socialista/ marxista, o professor, o formador de professores, o trabalhador jovem intelectualizam as questões sociais, políticas, culturais e econômicas do ponto de vista do que Gramsci $(1971 ; 2000)$ chamou de bom senso, de uma perspectiva de consciência de classe, ou, para citar uma injunção 
Neo-Fascismo, Capitalismo e Educadores Marxistas

marxista clássica do Manifesto Comunista (Marx; Engels 1848/2010), que "[...] a principal tarefa política que os comunistas enfrentam é a formação do proletariado em uma classe”, isto é, uma classe para si mesma, uma classe consciente de si mesma como classe na relação Capital-Trabalho (Marx, 1999). Aqui reside a importância pedagógica dos marxistas, de partido, de organização, de folhetos, de jornais, de brochuras, de livros e de redes sociais; aqui, assim como na sala de aula, nas conversas e nos discursos, desempenhamos o papel da análise socialista, da pedagogia revolucionária, de conectar o aqui e o agora a uma greve de aluguel, um comício pró-imigrante, uma marcha antiausteridade, um piquete de um empregador com contrato zero horas, uma ocupação de uma loja de propriedade de empresa multinacional evitando impostos: aqui está a pedagogia marxista essencial.

Os marxistas são necessários, necessários para liderar e desenvolver mudanças de consciência, uma mudança na consciência de classe, e para desempenhar um papel contributivo na organização para substituir o capitalismo.

Para concluir: a tarefa dos professores marxistas/socialistas democráticos e dos socialistas e marxistas contra-hegemônicos e igualitários, estudantes, trabalhadores culturais, formuladores de políticas e ativistas é:

1. expor e contestar as formas e a extensão em que a classe capitalista, por meio de seu poder econômico e de seu poder sobre a política fiscal e econômica dos governos que a servem, suprime e reprime tanto o salário direto quanto o salário em detrimento do lucro capitalista, por exemplo, na proporção da renda nacional, e redução/subfinanciamento/redução do salário social (sistemas de assistência social e saúde pública e educação e assistência social) - quanto por meio da força bruta para suprimir sindicatos e demitir trabalhadores;

2. Além disso, explicar e desenvolver a consciência, a compreensão crítica marxista da relação Trabalho-Capital, que o capitalismo é a exploração da força de trabalho dos trabalhadores através do roubo da mais-valia produzida pelos trabalhadores, roubada deles pelos capitalistas (e pelas organizações estatais capitalistas) na forma de lucro;

3. expor, organizar e ensinar contra a violência real e simbólica do Estado e da classe capitalista contra a classe trabalhadora (étnica e de gênero);

4. expor e contestar as formas e a extensão em que o Estado capitalista e seus aparelhos perpetuam e reproduzem seu poder, o de sua classe, por meio dos aparelhos ideológicos e repressivos do Estado (como a mídia, o processo de escolarização, a educação continuada e os sistemas universitários, e o sistema parlamentarista eleitoral);

5. especificamente, a maneira como eles o fazem ao rebaixar e ridicularizar o capital cultural e os conhecimentos da classe trabalhadora (étnica e de gênero), por meio do que Pierre Bourdieu chamou de arbitrário cultural e violência simbólica - a maneira como os alunos da classe trabalhadora são amplamente ensinados que eles são relativa- 
mente inúteis, e os alunos da classe alta são ensinados que controlarão e herdarão a Terra, e alguns alunos da classe média são ensinados a administrá-la para eles;

6. defender, propagar, organizar, agitar e implementar políticas e mudanças igualitárias marxistas democráticas na sociedade e na economia de forma ampla, e não apenas dentro das paredes da sala de aula.

Recebido em 15 de maio de 2021 Aprovado em 20 de julho de 2021

\section{Notas}

1 Tradução de Vinícius Neves de Cabral

2 Nota do tradutor (N.T.): Comprehensive schools, na Inglaterra, são escolas abertas ao público e que não selecionam os alunos com base em desempenho acadêmico ou testes de pré-seleção. Nas selective schools, por sua vez, os alunos são escolhidos a partir de rigorosos critérios acadêmicos.

3 N.T. Creeping Fascism ainda sem tradução em português.

4 Disponível em: <http://www.ieps.org.uk/publications/online-papers-davehill/s.

5 N.T. Open University

6 Para uma discussão entre educadores Marxistas anticapitalistas revolucionários e educadores marxianos ou educadores reformistas de esquerda, ver Farahmandpur (2004); McLaren e Farahmandpur (2005), Rikowski (2006; 2019); Kelsh e Hill (2006); Hill (2009); Banfield, (2011; 2015); McLaren (2010; 2013; 2021); Malott (2011), por um lado, e Apple (2006), Saltman (2010) e McGrew (2011).

\section{Referências}

ALTHUSSER, Louis. Contradiction and Overdetermination. 1962. Available at: <https://www.marxists.org/reference/archive/althusser/1962/appendix.htm>. Accessed on: 02 Feb. 2021.

ALTHUSSER, Louis. Ideology and Ideological State Apparatuses. In: ALTHUSSER, Louis. Lenin and Philosophy and Other Essays. London: New Left Books, 1971. Available at: <https://www.marxists.org/reference/archive/althusser/1970/ideology.htm>. Accessed on: 02 Feb. 2021.

ANYON, Jean. Marx and Education. London: Routledge, 2011.

APPLE, Michael. Review Essay: rhetoric and reality in critical educational studies in the United States. British Journal of Sociology of Education, v. 27, n. 5, p. 679-687, 2006.

AU, Wayne. The Dialectical Materialism of Paulo Freire's Critical Pedagogy. Revista Reflexão e Ação, Santa Cruz do Sul, v. 25, n. 2, p. 171-195, 2017.

BALL, Stephen. Class Strategies and the Educational Market: the middle classes and social advantage. London: Routledge Falmer, 2003.

BANFIELD, Grant. Looking for Marx: a review of Marx and Education by Jean Anyon. Journal for Critical Education Policy Studies, v. 9, n. 2, 2011. Available at: <http://www.jceps.com/archives/671>. Accessed on: 02 Feb. 2021.

Educação \& Realidade, Porto Alegre, v. 46, n. 3, el17660, 2021. 
Neo-Fascismo, Capitalismo e Educadores Marxistas

BANFIELD, Grant. Marx and Education: working with the revolutionary educator. Journal for Critical Education Policy Studies, v. 13, n. 3, 2015. Available at: <http://www.jceps.com/archives/2792>. Accessed on: 02 Feb. 2021.

BHATTACHARYA, Tithi. Social Reproduction Theory: remapping class, recentering oppression. London: Pluto Press, 2017.

BOURDIEU, Pierre; PASSERON, Jean-Claude. Reproduction in Education, Society and Culture. London: Sage Publications, 1977.

BOWLES, Samuel; GINTIS, Herbert. Schooling in Capitalist America. London: Routledge and Kegan Paul, 1976.

BUARQUE, Chico; VELOSO, Caetano; SALGADO, Sebastião; ANTUNES, Arnaldo; RIBEIRO, Djamila; HATOUM, Milton; COSTA, Petra et al. Democracy and freedom of expression are under threat in Brazil. The Guardian, 7 feb 2020. Available at: <https://www.theguardian.com/commentisfree/2020/feb/07/ democracy-and-freedom-of-expression-are-under-threat-in-brazil $>$. Accessed on: 02 Feb. 2021.

BUKHARIN, Nicolai; PREOBRAZHENSKY, Ievguêni. The ABC of Communism. London: Penguin Books, 1969. Available at: <https://www.marxists.org/archive/bukharin/works/1920/abc>. [1922] Accessed on: 02 Feb. 2021.

BUSBY, Mattha. Schools in England told not to use material from anti-capitalist groups. The Guardian, 27 Sept 2020. Available at: <https://www.theguardian. com/education/2020/sep/27/uk-schools-told-not-to-use-anti-capitalist-material-in-teaching >. Accessed on: 02 Feb. 2021.

CASTANHEIRA, Patrícia; COSTA, Jorge Adelino. From a Collegially Elected Council to a Director: the evolution of Portuguese school management. Procedia Social and Behavioral Sciences, v. 15, 2011. Available at: <www.sciencedirect>. Accessed on: 02 Feb. 2021.

DOE, B. Improving London's Schools. Times Educational Supplement, 23 mar. 1984.

DOE, B. The Thomas Report. Times Educational Supplement, 18 jan. 1985.

EDWARDS, Gail; HILL, Dave; BOXLEY, Simon. Critical Teacher Education for Economic, Environmental and Social Justice. Journal for Critical Education Policy Studies, v. 16, n. 3, 2018. Available at: <http://www.jceps.com/archives/49021>. Accessed on: 02 Feb. 2021.

FARAHMANDPUR, Ramin. Essay review: A Marxist critique of Michael Apple's Neo-Marxist Approach to Educational Reform. Journal for Critical Education Policy Studies, v. 2, n. 1, 2004. Available at: <http://www.jceps.com/wp-content/uploads/PDFs/02-1-4.pdf>. Accessed on: 02 Feb. 2021.

FASSBINDER, Samuel; MCLAREN, Peter. The 'Dirty Thirty's' Peter McLaren Reflects on the Crisis of Academic Freedom. MROnline, 6 apr. 2006. Available at: $<$ https://mronline.org/2006/04/06/the-dirty-thirtys-peter-mclaren-reflectson-the-crisis-of-academic-freedom/>. Accessed on: 02 Feb. 2021.

FAULKNER, Neil; DAHI, Samir; HEARSE, Phil; SYEDA, Seema. Creeping Fascism: what it is and how to fight it. London: Public Reading Rooms, 2019.

FAULKNER, Neil; HEARSE, Phil; HANNAH, Simon; FORTUNE, Rowan; FORTUNE, Nina. System Crash: an activist guide to the coming democratic revolution. chapter 6 the new fascism, 2021. Available at: <https://anticapitalistresistance. org/chapter-6-the-new-fascism/>. Accessed on: 02 Feb. 2021.

FLOUD, Jean; HALSEY, A.H; MARTIN, F.M. Social Class and Educational Opportunity. London: Heinemann, 1957. 
FOLEY, Ann; MORRIS, Doug; GOUNARI, Panayota; AGOSTINONE-WILSON, Faith. Critical Education, Critical Pedagogies, Marxist Education in the United States. Journal for Critical Education Policy Studies, v. 13, n. 3, 2015. Available at: <http://www.jceps.com/archives/2758>. Accessed on: 02 Feb. 2021.

FORD, Derek. Communist Study: education for the commons. Lanham, MD, USA: Lexington Books, 2016.

GIBSON, Richard. The Dead End at Freire. Speech at Canadian Society for the Study of Education, University of British Columbia, Vancouver BC, 2008. Available at: <http://www.richgibson.com/rouge_forum/CSSE2008/GibsonCSSE2008.htm>. Accessed on: 02 Feb. 2021.

GIROUX, Henry. Theories of Reproduction and Resistance in the New Sociology of Education: a critical analysis, Harvard Education Review, v. 55, n. 3, p. 257293, 1983. Available at: <https://www.academia.edu/3638580/Theories_of_Resistance_and_Reproduction_in_the_New_Sociology_of_Education $>$. Accessed on: 02 Feb. 2021.

GIROUX, Henry. Theory and Resistance in Education: towards a pedagogy for the opposition. Westport, Connecticut, London: Bergin \& Garvey, 2001.

GONZALEZ, Aldo Ocampo; RIKOWSKI, Glenn. Interview with Glenn Rikowski on Marxism, Critical Pedagogy and Inclusive Education: discussions for a revolutionary discourse. Revista Izquierdas, v. 45, n. 1 p. 260-276, 2019. Available at: $<$ https://www.aacademica.org/aldo.ocampo.gonzalez/9.pdf >. Accessed on: 02 Feb. 2021.

GRAMSCI, Antonio. (1971/2000). Selections from the Prison Notebooks. New York: International Publishers Co, 2000. [1971] Available at: <https://www.marxists.org/archive/gramsci/prison_notebooks/selections.htm>. Accessed on: 02 Feb. 2021

HALSEY, Anthony Heath. Educational Priority Volume 1: EPA problems and policies. London: HMSO, 1972.

HALSEY, Anthony Heath; HEATH, A.F; RIDGE, J. M. Origins \& Destinations: family, class and education in modern britain. Oxford: Oxford University Press, 1980.

HILL, Dave. Teacher Education and Training: a left critique. Forum (for promoting 3-19 comprehensive education), v. 6, n. 3, p. 74-76, 1994. Available at: <http://www.wwwords.co.uk/forum/content/pdfs/36/Forum_36_3.pdf>. Accessed on: 02 Feb. 2021.

HILL, Dave. Equality in Primary Schooling: the policy context, intentions and effects of the conservative 'reforms'. In: COLE, Mike; HILL, Dave; SHAN, Sharanjeet (Ed.). Promoting Equality in Primary Schools. London: Cassell, 1997. Available at: <http://www.ieps.org.uk/publications/online-papers-dave-hill/>. Accessed on: 02 Feb. 2021.

HILL, Dave. State Theory and The Neo-Liberal Reconstruction of Schooling and Teacher Education: a structuralist neo-marxist critique of postmodernist, quasi-postmodernist, and culturalist neo-marxist theory. The British Journal of Sociology of Education, v. 22, n. 1, p. 137-157, 2001. Available at: <http://www. ieps.org.uk/media/1162/brit-jnl-sociol-of-educ-22-1-2001-dave-hill-state-theory-article.pdf>. Accessed on: 02 Feb. 2021.

HILL, Dave. Brief Autobiography of a Bolshie Dismissed. 2004. Available at: <http://www.ieps.org.uk/media/1001/bolsharticle.pdf>. Accessed on: 02 Feb. 2021.

Educação \& Realidade, Porto Alegre, v. 46, n. 3, el17660, 2021. 
Neo-Fascismo, Capitalismo e Educadores Marxistas

HILL, Dave. State Theory and the Neoliberal Reconstruction of Schooling and Teacher Education. In: FISCHMAN, Gustavo; MCLAREN, Peter; SÜNKER, Heinz; LANKSHEAR, Colin (Ed.). Critical theories, Radical Pedagogies and Global Conflicts. Boulder; Colorado: Rowman and Littlefield, 2005.

HILL, Dave. Culturalist and Materialist Explanations of Class and 'Race': critical race theory, equivalence/ parallelist theory, and marxist theory. Cultural Logic: an electronic journal of marxist theory \& practice, v. 12, p. 1-52, 2009. Available at: <file:///C:/Users/User/AppData/Local/Temp/191552-Article\%20 Text-217141-1-10-20190325.pdf>. Accessed on: 02 Feb. 2021.

HILL, Dave. A Socialist Manifesto for Education. Brighton: Institute for Education Policy Studies, 2010. Available at: <http://www.ieps.org.uk/media/1003/ socialistmanifestofored.pdf $>$. Accessed on: 02 Feb. 2021.

HILL, Dave. A Socialist Education Policy. Forum for Promoting 3-19 Comprehensive Education. 2015. Available at: <http://www.wwwords.co.uk/rss/ abstract.asp?j=forum\&aid=6224>. Accessed on: 02 Feb. 2021.

HILL, Dave. Marxist Education Against Capitalism. In: RASINSKI, Lotar; HILL, Dave; SKORDOULIS, Kostas (Ed.). Marxism and Education: international perspectives on theory and action. New York; London: Routledge, 2018.

HILL, Dave. Marxist Education and Teacher Education Against Capitalism in NeoLiberal/NeoConservative/NeoFascist/ Times. Cadernos do GPOSSHE Online, 2019a. Estadual do Ceará Fortaleza, Brazil (Grupo de Pesquisa Ontologia do Ser Social, História, Educação e Emancipação Humana). Available at: <https://revistas.uece.br/index.php/CadernosdoGPOSSHE/article/view/1524/127 5?fbclid=IwAR349OKt6lL5HRD1SiJK-6Iv7EwlQLoJpbNIVQqrjvH-LW89JHT5fAeXdFA>. Accessed on: 02 Feb. 2021.

HILL, Dave. Marxism and Teacher Education. In: PETERS, Michael (Ed.). Encyclopedia of Teacher Education, 1-6. Singapore: Springer Singapore, 2019b.

HILL, Dave. Marxist Public Policy Principles: schooling and teacher education training. Educazione Aperta, n. 6, 2019c. Available at: <http://educazioneaperta.it/>. Accessed on: 02 Feb. 2021.

HILL, Dave; COLE, Mike; WILLIAMS. C. Equality and Primary Teacher Education. In: COLE, Mike; HILL, Dave; SHAN, Sharanjeet (Ed.). Promoting Equality in Primary Schools. London: Cassell. 1997. Available at: <http://www.ieps.org. uk/publications/online-papers-dave-hill/>. Accessed on: 02 Feb. 2021.

ILEA (Inner London Education Authority). Improving Secondary Schools - a summary of the Hargreaves report. London: ILEA, 1984

JONES, Ken. Right Turn: the conservative revolution in education. London: Hutchinson Radius, 1989.

JONES, Ken. Education in Britain, 1944 to the Present. Cambridge: Polity, 2003.

KELSH, Deb; Hill, Dave. The Culturalization of Class and the Occluding of Class Consciousness: the knowledge industry in/of education. Journal for Critical Education Policy Studies, v. 4, n. 1, 2006. Available at: <http://www.jceps.com/? pageID=article\&articleID=59>. Accessed on: 02 Feb. 2021.

MAISURIA, Alpesh. Labour Need to Commit to a Comprehensive Review of Private Education. Private School Reform, 17 Feb. 2020. Available at: <https:// www.privateschoolreform.co.uk/opinion/labour-need-to-commit-to-a-comprehensive-review-of-private-education>. Accessed on: 02 Feb. 2021.

MALOTT, Stephenson. Pseudo-Marxism and the Reformist Retreat from Revolution: a critical essay review of Marx and Education. Journal for Critical Edu- 
cation Policy Studies, v. 9, n. 1, 2011. Online: <http://www.jceps.*com/index.ph p?pageID=article\&articleID=206>. Accessed on: 02 Feb. 2021.

MARX, Karl. The Poverty of Philosophy. 1999. [1847]. Available at: <https:// www.marxists.org/archive/marx/works/1847/poverty-philosophy/>. Accessed on: 02 Feb. 2021.

MARX, Karl. The Eighteenth Brumaire of Louis Bonaparte. 1999. [1852]. Available at: <https://www.marxists.org/archive/marx/works/1852/18th-brumaire/>. Accessed on: 02 Feb. 2021.

MARX, Karl; ENGELS, Friedrich. The Communist Manifesto. Marxist Internet Archive, 2010. [1848]. Available at: <https://www.marxists.org/archive/marx/ works/download/pdf/Manifesto.pdf>. Accessed on: 02 Feb. 2021.

MCGREW, Ken. On Being Holier-Than-Thou: a critique of curry malott's 'pseudo-marxism' and the reformist retreat from revolution. Journal for Critical Education Policy Studies, v. 9, n. 1, 2011. Available at: <http://www.jceps.com/ index.php?pageID=article\&articleID=222>. Accessed on: 02 Feb. 2021.

MCLAREN, Peter. Che Guevara, Paulo Freire and the Pedagogy of Revolution. Rowman \& Littlefield, 2000.

MCLAREN, Peter. Revolutionary Critical Pedagogy. Interactions: UCLA journal of education and information studies, v. 6, n. 2, 2010. Available at: <http://escholarship.org/uc/item/7qj2b570>. Accessed on: 02 Feb. 2021.

MCLAREN, Peter. Critical Pedagogy Against Capitalist Education- a Socialist Alternative. Global Education Magazine, 2013. Available at: <http://www.globaleducationmagazine.com/critical-pedagogy-againstcapitalist-schoolingsocialist-alternative-interview-peter-mclaren/>. Accessed on: 02 Feb. 2021.

MCLAREN, Peter. Revolutionary Critical Pedagogy: staking a claim against the macrostructural unconscious. Critical Education, v. 7, n. 8, p. 1-43, 2016. Disponível em: <https://ices.library.ubc.ca/index.php/criticaled/article/ view/186144>. Accessed on: 02 Feb. 2021.

MCLAREN, Peter. Revolutionary Pedagogy. In: THEMELIS, Spyros (Ed.) Critical Reflections on the Language of Neoliberalism in Education. London: Routledge, 2021.

MCLAREN, Peter; FARAHMANDPUR, Ramin. Teaching Against Imperialism and Global Capitalism. Lanham, MD, USA: Lexington Books, 2005.

RASINSKI, Lotar; HILL, Dave; SKORDOULIS, Kostas (Ed.). Marxist Education Against Capitalism in Neoliberal / Neoconservative Times. London; New York: Routledge, 2018.

REAY, Diane. Miseducation: inequality, education and the working classes. Bristol: The Policy Press, 2018.

RIKOWSKI, Glenn. In Retro Glide. Journal for Critical Education Policy Studies, v. 4, n. 2, 2006. Available at: <http://www.jceps.com/?pageID=article\&article ID=81>. Accessed on: 02 Feb. 2021.

RIKOWSKI, Glenn. Education Crises as Crises for Capital. Theory in Action, v. 12, n. 3, p. 128-172, Jul. 2019. Available at: <https://rikowski.wordpress. com/2019/08/25/education-crises-as-crises-for-capital-2/>. Accessed on: 02 Feb. 2021.

SALTMAN, Kenneth. The Gift of Education: public education and venture philanthropy. New York: Palgrave Macmillan, 2010. 
SIMON Brian. Education and the Labour Movement, 1870-1920. London: Lawrence and Wishart, 1965.

SIMON, Brian. The Politics of Education Reform, 1920-1940. London: Lawrence and Wishart, 1978.

STAŃCZYK, Piotr. The Critique of the Critical Critique of Critical Pedagogy: Freire, Suchodolski and the materialist pedagogy of emancipation. Critical Education, v. 12, n. 4, p. 1-24, 2021. Available at: <http://ojs.library.ubc.ca/index. php/criticaled/article/view/186502>. Accessed on: 02 Feb. 2021.

THOMAS, Norman. Improving Primary Schools: report of the committee on primary education chaired by norman thomas. London: ILEA, 1985.

VYGOTSKY, Lev. Thinking and Speech. 1934. Available at: <https://www.marxists.org/archive/vygotsky/works/words/Thinking-and-Speech.pdf>. Accessed on: 02 Feb. 2021.

WOODS, Andrew. Why is the Brazilian right afraid of Paulo Freire? Open Democracy, 2 July 2020. Available at: <https://www.opendemocracy.net/en/democraciaabierta/why-is-the-brazilian-right-afraid-of-paulo-freire/>. Accessed on: 02 Feb. 2021.

Dave Hill é um acadêmico e ativista marxista, editor-chefe da Journal for Critical Education Policy Studies (www.jceps.com) e editor da série Routledge Studies in Education, Neoliberalism and Marxism. Ele é Professor Emérito/Visitante/Pesquisador/Doutor Honorário em universidades na Inglaterra, Grécia, Chile e China. Lutou cinco eleições gerais na Europa e no Reino Unido para o Partido Trabalhista e depois para a Coalizão Socialista e Sindical, foi líder de um grupo de conselheiros trabalhistas e delegado sindical/representante sindical eleito por uma década.

ORCID: https://orcid.org/0000-0002-1412-7438

E-mail: davehilljceps@gmail.com / dave.hill@aru.ac.uk

Editora-responsável: Carla Vasques

Este é um artigo de acesso aberto distribuído sob os termos de uma Licença Creative Commons Atribuição 4.0 Internacional. Disponível em: <http:// creativecommons.org/licenses/by/4.0>. 